\title{
"A Child is as important as Life": Reflections on the Value of Children from Infertile Couples
}

\author{
Oluwakemi S. Iwelumor ${ }^{1,2}$, Shariffah Suraya Syed Jamaludin ${ }^{2 \star}$, Tayo O. George ${ }^{3}$, Seun K. Babatunde ${ }^{4}$, Olawale Y. Olonade ${ }^{3}$ \\ ${ }^{1}$ Department of Sociology, College of Business and Social Sciences, Landmark University, Nigeria; ${ }^{2}$ School of Social Sciences, \\ University Sains Malaysia, Malaysia; ${ }^{3}$ Department of Sociology, College of Business and Social Sciences, Covenant University, \\ Ota, Nigeria; 4Independent Researcher, Ilorin, Nigeria.
}

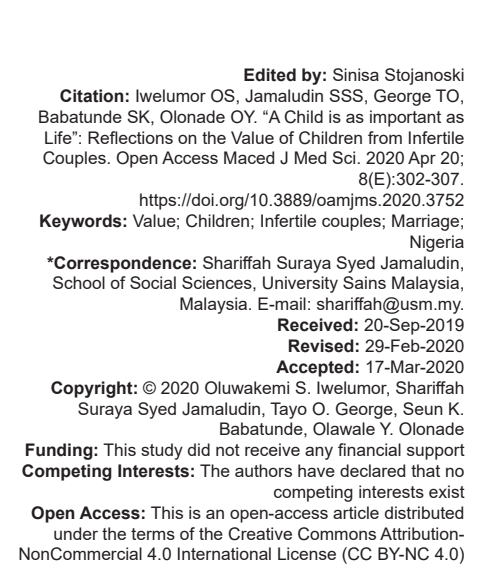

Abstract

BACKGROUND: Most African societies have no tradition of idealized celibacy or voluntary childlessness. Although the norms on parenthood are changing, adults are customarily expected to marry and bear children.

AIM: This study examined the perceived value of children among infertile couples in Kwara South, Nigeria.

METHODS: Semi-structured interviews were conducted with seven infertile couples recruited through snowball sampling technique. Data were organized using ATLAS.ti 8 and analyzed by thematic analysis.

RESULTS: The study revealed that perceptions of the value of children are embedded in sociocultural norms and are strongly linked to religion, patriarchy, and the need for family/marriage sustainability. Childbearing was perceived as the fulfillment of divine injunction; as such, children were regarded as divine. While women believed children are sources of fulfillment and balanced life, most men saw them as life itself. Boys are collectively thought to ensure lineage security and confer honor and prestige on men. A child is believed to give women a permanent seat in marriage.

CONCLUSIONS: These insights on the values of children within the Nigerian cultural context can be inculcated in programs and services targeted at alleviating the effect of infertility on childless couples. Innovative cultural programs that will increase the worth of the girl child are also encouraged.

\section{Introduction}

In every country of the world, there is a not too silent order for human procreation. This is expressly true of African countries where every couple is expected to desire and bear children. Although many assume childbearing is a natural occurrence, they would spontaneously achieve sometime along their life course, many couples fall short of achieving this through infertility. Infertility, as a reproductive health problem, has the highest-burden on people in developing countries [1], [2], [3], [4]. It is culturally defined in Nigeria as in most Sub-Saharan Africa as childlessness or failure of couples to achieve desired pregnancy or live birth within the $1^{\text {st }}$ year of marriage [5], [6], [7].

Values are subjective constructs; hence, variations in the perceptions of involuntary childlessness stem from different beliefs on marriage, parenthood, children, and family across societies. Many nonwestern cultures are guided by pronatalist principles that make biological parenthood obligatory. As such, childlessness in all its forms is seen as social deviance [8], and it is socially unacceptable in marriage [1]. Several studies in sub-Saharan Africa have shown that being childless is traumatic for most infertile couples. It is seen as a major life crisis at the individual, family, and community level with seemingly insurmountable consequences [3]. It challenges their social and moral identities [9], [10]. In worse cases, infertile persons, especially women, are seen as harbingers of evil to people and communities [5], [11].

Perceptions of the values of children are intricately linked with culture. Determining these values is somewhat difficult. It depends on several factors such as the social history and prevailing social norms in a particular society, personal circumstances, and social situations of a people [2]. Children from antiquity are perceived to be important. Several studies in developing nations have shown that the values of children are broadly socio-cultural and -economic [12].

While many studies have examined the value of children by obtaining information from general populations, the perceptions of infertile persons remain underexplored [4], [5], [8], [13], [14], [15]. The values of children, as explained in this study, reflect the perceptions of infertile couples. These could reveal how they make meaning of their childless situations and throw light on the reasons for their search for biological parenthood. 


\section{Methods}

This study adopted a qualitative phenomenological design to analyze the cultural values of children among infertile couples. The study was carried out in Kwara South, a senatorial district in Kwara State, Nigeria. The state is said to be the fifth-highest user of contraceptives among couples in Nigeria, with a total fertility rate of 4.4, the seventh-lowest in the country [16]. The district is home to many cultures, chief of which are Igbomina, Ekiti, and Ibolo people. Although the majority of the people are adherers of the Christian and Islamic faiths, they firmly live by the tenets of the African culture chief of which are supernaturalism and patriarchy [16].

Semi-structured in-depth interviews were conducted with seven infertile couples, recruited through snowball sampling. Spouses were interviewed separately. Four key informants were also purposively selected on the basis of their specialty, expertise, popularity, indigeneship, and willingness to participate in the research. Interviews were conducted in the preferred language of participants, usually English or Yoruba language. All participants gave informed consent before the commencement of interviews. The approval to conduct this study was obtained from the University of Ilorin Ethical Review Committee. All audio recordings were entirely transcribed. Data were analyzed by thematic analysis following the stages itemized by Braun, Clarke [17]. Codes were derived inductively. Those were later grouped into categories and themes using labels derived from participants' words. The quality of this study was guided by the evaluation criteria of Denscombe [18].

\section{Results}

All the participants in the study are referred by pseudo names in compliance with the ethic of confidentiality guiding this research. All the couples recruited for the in-depth interviews were married and experiencing primary infertility. The youngest of the couples, Debbie and Tunde aged 32 and 34 respectively, had been married for 3 years. Debbie is a sales representative who holds a Nigeria Certificate in Education. Her husband, an artisan, holds a Senior Secondary Certificate of Education. The couple earns about $\$ 85$ monthly. The couple with the most prolonged duration of infertility in the study was Iyanu, a 42-yearold teacher and Olopade, her 52-year-old husband, who is a civil servant who has been married for 22 years. All the women were in their reproductive years (32-48) at the time of the study.

Key informants were people who relate with infertile couples on regular bases and participate actively in managing their situations. They include Mrs. Aina, an experienced 68-year-old female traditional birth attendant cum traditional healer who practices both Christianity and African traditional religion, Mr. Falola, a 60-yearold revered native health-care provider who claimed he inherited his healing powers and has been practicing for more than 40 years, Alhaji Usman, a 43-year-old renown Islamic healer, and Pastor Mark, a 58-year-old prophet, who has an active ministry for over 30 years.

\section{Themes and subthemes}

The main themes and subthemes extracted from the study as the values of children and childbearing are presented in Figure 1.

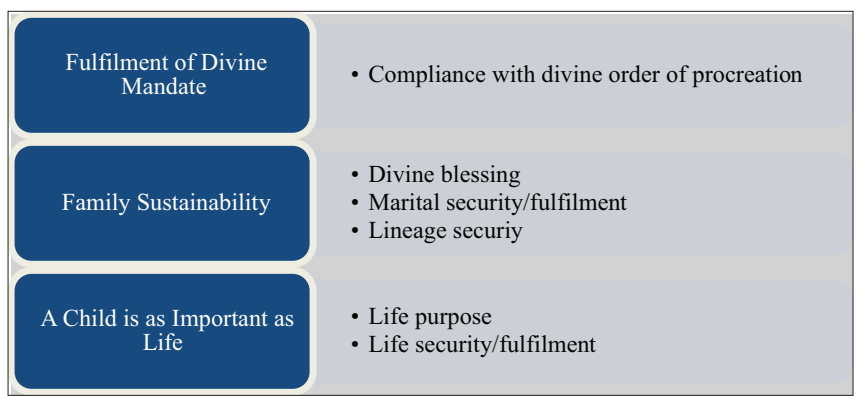

Figure 1: Themes and subthemes on the values of children derived from the study

\section{Fulfillment of divine mandate}

Childbearing was perceived collectively as compliance with the order of procreation. The value of children based on this perception can, therefore, be inferred from their capacity to ensure compliance with this religious order around which human existence revolves. This perception was well articulated by Olopade and Felicia, a 43-year-old university graduate and an entrepreneur who has been married for 15 years. She affirmed that childbearing is a commandment while Olopade averred that a biological child fulfills that commandment.

"A child is a commandment from God that everybody must-have... God did not say that some, $\mathrm{He}$ said, be fruitful and multiply" (Felicia).

"Having a child is a fulfillment of God's divine injunction to increase and multiply. God's plan for us all is to be fruitful and multiply" (Olopade).

The majority of the participants held that the desire for childbearing is innate, and everyone desires children, whether they come early or later in life. For example, Tunde claimed that "there is nobody that can come to the world and say he does not want a child." This belief was corroborated by Alhaji Usman, one of the key informants who works as an Islamic cleric and healer. He asserted that "it is human nature to want to have children." Shade, a housewife who has also been 
married for 11 years, reported it is unrealistic that a person would not desire children. However, she was confident that "not everyone will have them."

\section{Family sustainability}

This theme has three subthemes: Divine blessing, marital security/fulfillment, and lineage security.

\section{Divine blessing}

All the study participants valued children as divine blessings. While many defined them as "God's gifts," "God's blessings in marriage and family," others believed they are the "promised fruits of marriage" from God. This perception was supported by Pastor Mark, who has been ministering for over 30 years, with quotes from the Bible, "the Lord said thy children would be like olive plants round about your table... (Ps 127:3, 128: 3-4)."

Some participants went further to differentiate between "good" and "bad" children. They reported that a good child is from God, and children from other sources could be portents of death to parents. This view was, however, further clarified by a key informant, Mr. Falola. $\mathrm{He}$ explained that the children are not the harbingers of evil but their parents who fail to perform their vows.

"Some children are gotten from the gods. During getting these children from these gods, most parents make pledges which they later find difficult to fulfill... due to civilization or other reasons. This might lead the gods to afflict the family until the pledges are performed" (Falola).

\section{Marital security/fulfillment}

The majority of the couples equated marriage with childbearing. They averred that children are needed in every home, and they are significant to the survival of unions. Debbie, for instance, asserted that "without babies, there is no marriage. Marriage, to me, is basically for children." Ola, a 39-year-old graduate, who claimed to be a Christian by birth and a Muslim by marriage, held that "a child is a marriage, without children, there is no marriage." Been married for 7 years without a child, she believed that "it is better to be pregnant before any marriage ritual is performed to be safe." Virtually all the participants affirmed that the purpose or essence of marriage was to bear children and that childbearing is compulsory by the social standard.

The women reported that a child is needed to "seal a marriage" and "establish a home." More so, children are valued because they "give joy to unions," "peace," and "make the home stable." The success of a child is also thought would give marital fulfillment to parents. Shade and Ola expressly illustrated these views.
"Children are really the reason we marry. Without them, one cannot be really happy, no matter how happy you are with your husband. It will be just a matter of time before the marriage falls apart" (Shade).

"I'm sometimes scared because a woman without a child has no permanent stay in her husband's house, no matter what. Although my husband has low sperm count, I would not want a situation where my husband will be healed, and I will have a problem. Men are always gentle when the problem is from them; if there is a little change, they can easily impregnate another woman" (Ola).

\section{Lineage security}

The findings of this study suggest that childbearing within marriage confers legitimate status on a child. All the participants held that children ensure the continuity of the family with a higher premium placed on males than females. Sons are highly esteemed and praised for lineage sustenance. For example, Wale, Shade's husband, and Jaffar claimed that without a son, marriage is incomplete.

"Marriage or family is incomplete without a child, especially a son. The essence of marriage is to have legitimate children and be happy and pass on the family lineage" (Wale).

"Children ensure continuity of family name, especially boys" (Jaffar).

Some of the women also shared this perception, adding that children ensure not only the survival of the family but also the whole society at large. Iyanu and Ayo, a businesswoman who has been married for 13 years, acknowledged these.

"Children are important to help to preserve the lineage or the name of the family from going into extinction. Without them, the continuity of society is also at stake because they will be the ones to become the next generation" (Iyanu).

"In our society, a family or marriage without a child is incomplete, especially a son. Having a male child means the family lineage will pass on" (Ayo).

In this same vein, Alhaji Usman argued that "the word "Dhurriyyah," which means children are mentioned thirty-two times in the holy Quran in nineteen different Surahs. For this reason, one cannot overemphasize the impact of children in the family and society in general."

\section{A child is as important as life}

This theme relates to the perceived existential value of children, as reported by study participants. It is explained using two subthemes, namely, life purpose and life security or fulfillment. 
Life purpose

Many of the participants reported that childbearing is the purpose of life and that having a child gives life meaning. This suggests that the inability to have a child makes life meaningless. Olopade conveyed this belief by asserting that the failure to father a child means being dead while alive. Falola, one of the key informants, also claimed that childlessness denotes a worthless life.

"A child is as important as life itself...; someone without a child is like what Yoruba people call 'a snake' that passes through rock without an impact" (Olopade).

"A child is a reward for a fulfilled life. A marriage without a child is a failed marriage. ...childlessness is like coming to this world without having anything to show for it" (Falola).

\section{Life security/fulfillment}

Children are valued because they are thought to give parents a sense of security at old age, validate adulthood, and improve overall life satisfaction. For example, Wale stated that "children are their parents" covering." He expatiated on this by saying that

"it is good to have good children to bury one. They are also like investments; you invest in them while you have the means so that when you are old, they will take care of you. They also ensure one's name does not perish especially male children. They give prestige to a man. Without a child, a man is no man; he will be seen as a boy amidst his friends and society" (Wale).

This opinion was supported by Dele, a 43-yearold entrepreneur who has been married for 13 years. He mentioned that

"the thought of having someone to take care of you when you are old and bury you brings peace, prestige, and honor to a man in his family, society, and amidst his friends" (Dele).

Aside from giving marital fulfillment, having surviving children is thought to make life stable and balance. Many were also of the opinion that childbearing is worth more than riches, while children are the best things one can have in life.

"No matter how successful a woman is, without a child, her life is in vain... If I were to choose between a child and wealth, with my experiences now, I would have gladly taken children" (Ayo).

\section{Discussion}

The meaning and significance childless women and men attach to children and childbearing may help to understand their plight with infertility better. Participants perceived childbearing as a divine order. This perception could have originated from the African theocentric worldview, which is supported by many contemporary religions. The participants firmly live by the tenets of the African culture chief of which is supernaturalism. According to Onyewuenyi [19] and Mbiti [20], African culture is appropriate with the demands of God. It is deemed a guide to take man closer to the Supreme Being who created him and approves of his culture. It is assumed that if one lives by the dictates of his culture here on earth, he will join God and the ancestors in the spiritual world. Thus, it was deduced from the study that natalism as ingrained in participants' worldview is given. Childless persons seek children in obedience to divine law (of reproduction), which is as important as other laws.

This finding is similar to reports by Tabong and Adongo [21] and Greil, McQuillan [22] who posited that the intent or desire for parenthood could be the driving force for seeking children. While this could be the case, this finding has revealed that the value of children and the reason for the strong desire and search for biological children among the infertile lies not only in conferring parenthood. Instead, it also stems from an actualization of the innate nature of women and men to conform to a divine mandate.

This study also revealed that childbearing has marital and existential values. While childbearing was seen as a divine mandate, a child was seen as a divine blessing. Children were perceived as gifts from God and the promised fruits of marriage as expressed by culture and as contained in the holy books, the Bible, and the Quran. This shows that notwithstanding the influence of contemporary religions and civilizations on participants, many view marriage as the most appropriate agency for procreation and life advancement. This is founded on the belief that childbearing is the prerogative of the married, and marriage provides the legitimate ground for childbearing. Therefore, a couple or spouse who is unable to bear children after marriage is frowned at and judged as guilty since childbearing is seen as a natural blissful manifestation of the acceptance or approval of marriage by God(s) [23].

While women believed children are sources of marital fulfillment and balanced life, most men equated children with life. Boys are collectively thought to ensure lineage security and confer more honor and prestige on men. Children are considered to make life worth living; they are makers of adulthood and are symbols of accomplishment. These findings are similar to the outcome of some studies that the primary purpose of marriage in most developing countries is to have children and marriages without children are incomplete and insecure [4], [8], [13], [24].

The main reason for marital insecurity in childless marriages could be inferred from the Nigerian kinship structure. According to Kyalo [25], the most important 
relationship within the Nigerian social structure is the consanguine relationship. This, however, is only possible through filial relationships within approved marital unions. The presence of biological children symbolizes the fulfillment of marriage contracts between families and clans, which in most cases, remain unbreakable. Thus, as asserted by most female participants, married women without children have no permanent seats in their homes/marriages since the birth of a child, guarantees their integration into the clan while, the birth of a male child ensures lasting membership.

Although every child, regardless of sex, has value to study participants, the desire of some for male children could stem from the urgency to have replacements at death. Some of the participants are old, and many do not have the financial resources to seek assisted reproduction continuously. Thus, some prefer to have male children as firstborns to immortalize their names and ensure they continue to exist even after death. This assurance to some would give them peace at death and make their passing pleasing and bearable.

The existential value of children, as inferred from participants' responses, has both secular and spiritual undertones. Many participants described childbearing as the purpose of marriage, while some described it as the purpose of life. Children are perceived to be existentially important because they give life meaning, make life stable, improve overall life satisfaction, and are regarded as the best things one can have in life. Although these values could amount to what is missing in participants' lives, they, however, correlate with findings from multinational studies on the existential significance of childbearing, childbirth, and children [26]

\section{Conclusion}

Childbearing is culturally mandatory, and it constitutes a core aspect of life in Kwara South, Nigeria. Biological parenthood is a social obligation that is inseparable from religion, personal/life fulfillment, and the need for family sustainability with a higher premium placed on the male child. The findings of this study have shown that regardless of the religion or social standing of couples, these values of children significantly contribute to the overall burden of infertility on childless couples in their quest for biological parenthood.

\section{References}

1. Van Balen F, Inhorn MC. Interpreting infertility: A view from the social science. In: Interpreting Infertility: Childlessness, Gender and Reproductive Technologies in Global Prospective. Berkley:
UCLA Press; 2002. https://doi.org/10.2307/3583249

2. Olonade O, Olawande TI, Alabi OJ, Imhonopi D. Maternal mortality and maternal health care in Nigeria: Implications for socioeconomic development. Open Access Maced J Med Sci 2019;7:849-55. https://doi.org/10.3889/oamjms.2019.041 PMid:30962850

3. Pennings $\mathrm{G}$. Ethical issues of infertility treatment in developing countries. ESHRE Monogr 2008;2008:15-20. https://doi. org/10.1093/humrep/den142

4. Sarkar S, Gupta P. Socio-demographic correlates of women's infertility and treatment seeking behavior in India. J Reprod Infertil 2016;17(2):123-32.

PMid:27141468

5. Okonofua FE, Harris D, Odebiyi A, Kane T, Snow RC. The socia meaning of infertility in Southwest Nigeria. Health Trans Rev 1997;7:205-20

6. Iwelumor OS, Suraya SS, Babatunde SK, Hayat MF. Sociocultural perceptions of infertility. Asia Proc Soc Sci 2019;4(2):165-7. https://doi.org/10.31580/apss.v4i2.790

7. Olu Pearce T. She will not be listened to in public: Perceptions among the Yoruba of infertility and childlessness in women. Reprod Health Matters 1999;7(13):69-79. https://doi. org/10.1016/s0968-8080(99)90114-3

8. Dimka RA, Dein SL. The work of a woman is to give birth to children: Cultural constructions of infertility in Nigeria. Afr $\mathrm{J}$ Reprod Health 2013;17(2):102-17.

PMid:24069756

9. Dhont N, Van de Wijgert J, Coene G, Gasarabwe A Temmerman M. "Mama and papa nothing": Living with infertility among an urban population in Kigali, Rwanda. Hum Reprod 2011;26(3):623-9. https://doi.org/10.1093/humrep/deq373 PMid:21216790

10. Hollos M, Larsen U, Obono O, Whitehouse B. The problem of infertility in high fertility populations: Meanings, consequences and coping mechanisms in two Nigerian communities. Soc Sci Med 2009;68(11):2061-8. https://doi.org/10.1016/j. socscimed.2009.03.008 PMid:19356835

11. Koster-Oyekan W. Infertility among Yoruba women: Perceptions on causes, treatments and consequences. Afr J Reprod Health 1999;3(1):13-26. https://doi.org/10.2307/3583225

12. Ombelet $W$. False perceptions and common misunderstandings surrounding the subject of infertility in developing countries. ESHRE Monogr 2008;2008(1):8-11. https://doi.org/10.1093/ humrep/den204

13. Dyer SJ. The value of children in African countries insights from studies on infertility. J Psychosom Obstet Gynecol 2007;28(2):69-77. https://doi.org/10.1080/01674820701409959 PMid: 17538814

14. Das Gupta M, Zhenghua J, Bohua L, Zhenming X, Chung W, Hwa-Ok B. Why is son preference so persistent in East and South Asia? A cross-country study of China, India and the Republic of Korea. J Dev Stud 2003;40(2):153-87. https://doi. org/10.1080/00220380412331293807

15. Meyers M, Weinshel M, Scharf C, Kezur D, Diamond R, Rait DS An infertility primer for family therapists: II. Working with couples who struggle with infertility. Fam Proc 1995;34(2):231. https:// doi.org/10.1111/j.1545-5300.1995.00231.x PMid:7589420

16. National Bureau of Statistics. Statistical Report on Women and Men in Nigeria; 2019. Available from: http://www.nigerianstat. gov.ng/index.phpdemographic. [Last accessed on 2019 Jun 17].

17. Braun V, Clarke V, Hayfield N, Terry G. Thematic Analysis. In: Liamputtong $\mathrm{P}$, editor. Handbook of Research Methods in Health Social Sciences. Singapore: Springer Singapore; 2019. 
p. 843-60. https://doi.org/10.1007/978-981-10-5251-4_103

18. Denscombe M. The Good Research Guide: For Small-scale Social Research Projects. United Kingdom: McGraw-Hill Education; 2014

19. Onyewuenyi I. Traditional African aesthetics: A philosophical perspective. In: The African Philosophy Reader. London; New York: Routledge; 1998.

20. Mbiti JS. African Religions and Philosophy. Portsmouth, New Hampshire: Heinemann; 1990.

21. Tabong PT, Adongo PB. Understanding the social meaning of infertility and childbearing: A qualitative study of the perception of childbearing and childlessness in Northern Ghana. PLoS One 2013;8(1):e54429. https://doi.org/10.1371/journal.pone.0054429 PMid:23342158

22. Greil A, McQuillan J, Slauson-Blevins K. The social construction of infertility. Soc Compass 2011;5(8):736-46. https://doi. org/10.1111/j.1751-9020.2011.00397.x

23. Olarinmoye AW. Who needs your opinion? Changing values of traditional marriage among the Yoruba South-western Nigeria. Glob J Appl Manag Soc Sci 2016;11:85-96.

24. Tabong PT, Adongo PB. Infertility and childlessness: A qualitative study of the experiences of infertile couples in Northern Ghana. BMC Pregnancy Childbirth 2013;13(1):72. https://doi. org/10.1186/1471-2393-13-72

25. Kyalo $P$. A reflection on the African traditional values of marriage and sexuality. Int J Acad Res Prog Educ Dev 2012;1(2):211-9.

26. Prinds C, Hvidt NC, Mogensen O, Buus N. Making existential meaning in transition to motherhood a scoping review. Midwifery 2014;30(6):733-41. https://doi.org/10.1016/j.midw.2013.06.021 PMid:23928210 